\title{
Femoral Distal Mucormycosis after a Knee Meniscectomy
}

\author{
Carlos Garces Zarzalejo, MD ${ }^{1}$ Michel Fakkas Fernandez, MD ${ }^{1}$ Marta Fernandez Sampedro, MD, PhD 2 \\ Luis Estelles Marcos, MD ${ }^{1}$ Marian De la Red Gallegos, MD ${ }^{1}$ Sergio Garcia Granja, MD ${ }^{1}$ \\ ${ }^{1}$ Department of Orthopeadic Surgery, Valdecilla University Hospital, \\ Santander, Cantabria, Spain \\ 2 Division of Infectious Diseases, Department of Medicine, Valdecilla \\ University Hospital, Santander, Cantabria, Spain \\ Address for correspondence Carlos Garces Zarzalejo, MD, \\ Department of Orthopeadic Surgery, Valdecilla University Hospital, Av. \\ Valdecilla S/N 39008 Santander, Cantabria, Spain \\ (e-mail: carlosgarceszarzalejo@gmail.com; cgarces@humv.es).
}

J Knee Surg Rep 2015;1:12-16.

\begin{abstract}
Keywords

- knee arthroscopy

- fungal infection

- osteomyelitis

- mucormycosis

- total knee arthroplasty

Although various complications have been reported following knee arthroscopy, postoperative infections are rare. The pathogens most commonly isolated in infections associated with arthroscopic surgery are Staphylococcus species. Fungal osteomyelitis remains a very unusual complication, but it is associated with severe consequences when it does occur. Only 10 cases of fungal osteomyelitis following anterior cruciate ligament $(\mathrm{ACL})$ reconstruction have been reported in the literature. To our knowledge, the case we report on here is the first mycotic infection following a routine arthroscopic knee procedure-a partial meniscectomy. Diagnosis of this type of complication represents a great challenge to orthopedic surgeons and physicians. Fungal infections should be suspected in patients with persistent signs and symptoms of septic arthritis following an arthroscopic procedure, despite conventional cultures consistently positive for bacteria, and normally adequate treatment using specific antibiotic therapy. Positive fungal cultures and the presence of mycotic structures in histopathologic samples confirm the diagnosis. Incorrect and delayed diagnoses are common, so extensive bone destruction is frequently found. For a successful resolution of fungal osteomyelitis, twostage procedures including radical debridement and prolonged antifungal treatment should be employed. The reconstructive stage may often require complex surgical techniques, including revision of total knee arthroplasty or arthrodesis.
\end{abstract}

Although many complications have been reported following knee arthroscopy, postoperative infections are rare. The reported prevalence of deep knee infection after this procedure has ranged from 0.3 to $1.7 \%^{1,2}$ The most commonly identified causative bacteria are staphylococci, Staphylococcus aureus being the most frequent species isolated. However, coagulase-negative staphylococci is increasingly recognized as a significant pathogen. ${ }^{2,3}$ In most cases, bacterial infections do not produce catastrophic results. Fungal infections can, however, occur.

received

April 10, 2013

accepted after revision

December 31, 2013

published online

February 26, 2014
Fungal osteomyelitis is a very rare complication after knee arthroscopic surgery, associated with severe consequences.

A review of the literature found only 10 reported cases of fungal osteomyelitis with extensive bone destruction, all following anterior cruciate ligament (ACL) reconstruction. The most commonly isolated species in these cases belonged to the genera Rhizopus (six cases), followed by Aspergillus (two cases), Candida albicans (one case), and Phycomycoses (one case).$^{1-6}$ In most of the cases reported, fungal infection was diagnosed based on histopathologic samples or fungal Tel: +1(212) 584-4662.

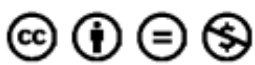

Copyright $\odot 2015$ by Thieme Medical Publishers, Inc., 333 Seventh Avenue, New York, NY 10001, USA.

License terms

$10.1055 / \mathrm{s}-0034-1370900$. ISSN 2326-2729. 


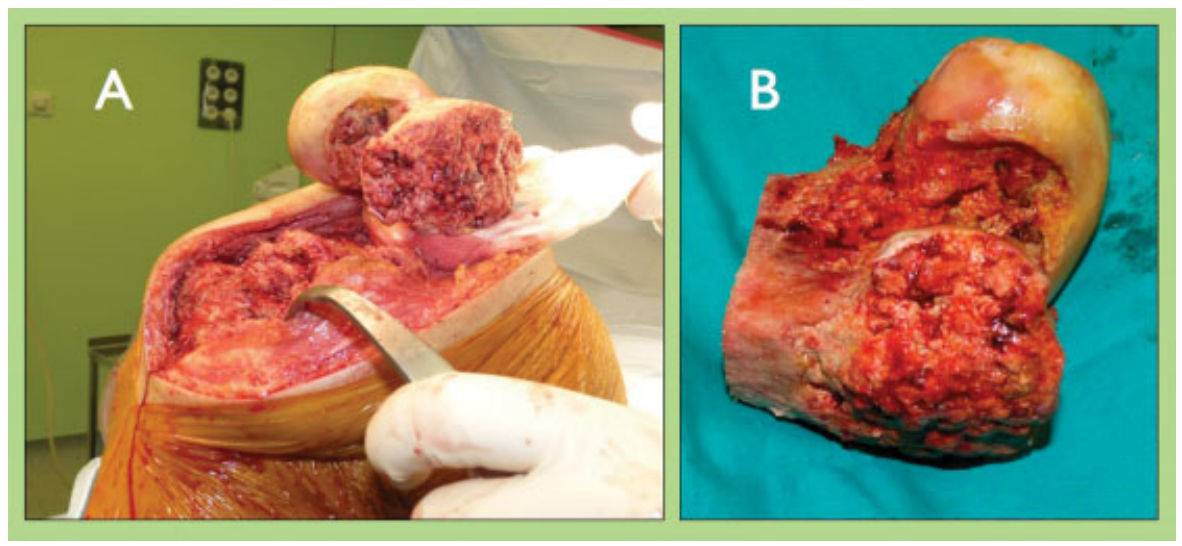

Fig. 1 (A, B) Intraoperative findings in open debridement and massive resection surgery: massive necrosis of cancellous bone in distal femur epiphysis.

cultures; the delayed diagnosis in these cases led to extensive and destructive bone lesions requiring complex reconstruction techniques using allografts, revision total knee replacements, or arthrodesis.

We describe a case of mucormycosis osteomyelitis after a simple arthroscopic meniscectomy. Despite several arthroscopic debridements and empirical broad-spectrum antibiotic treatment, there was no clinical improvement. Mycotic infection was diagnosed based on samples from the latest debridement and the fungal infection resulted in a cavitary lesion of the distal femur and tibial plateau. Prolonged antifungal treatment and two-staged reconstruction surgery was required to heal the infection and restore knee joint function.

\section{Case Report}

A 34-year-old healthy man underwent arthroscopic knee meniscectomy. Thirty days after the surgery, the patient presented to the hospital with swelling and persistent pain. Knee examination showed poor motion, redness, and warmth. An arthrocentesis produced $35 \mathrm{~mL}$ of turbid yellow fluid. Subsequently, three arthroscopic knee debridements were performed and empirical broad-spectrum antibiotic treatment was begun. The third arthroscopic examination revealed large areas of chondrolysis, with intraoperative culture samples positive for Rhizopus spp.

The patient was transferred to our hospital. He remained afebrile, with mild pain and limited range of motion. The white blood cell count was $10.1 \times 10^{3}$ cells/L, with erythrocyte sedimentation rate of $74 \mathrm{~mm} /$ hour and C-reactive protein of $11.3 \mathrm{mg} / \mathrm{dL}$; X-ray study revealed signs of tricompartmental osteoarthritis.

Liposomal amphotericin B, ceftazidime, and teicoplanin were administered initially. An open debridement surgery revealed massive necrosis of the distal femur epiphysis and tibial plateau. A wide synovectomy and extensive bone resection was performed on the tibial plateau and $9 \mathrm{~cm}$ of the distal femur. The residual bone defect was replaced with a gentamicin-loaded cement spacer (-Fig. 1).

Intraoperative joint fluid, synovial lining, and bone tissue samples were positive for Rhizopus spp. and Staphylococcus epidermidis. Histopathological examination revealed signs of acute osteomyelitis and nonseptate irregular fungiform structures compatible with Rhizopus spp. (-Fig. 2).

Antifungal treatment was continued for 3 months before the reconstruction surgery was performed, with a revision

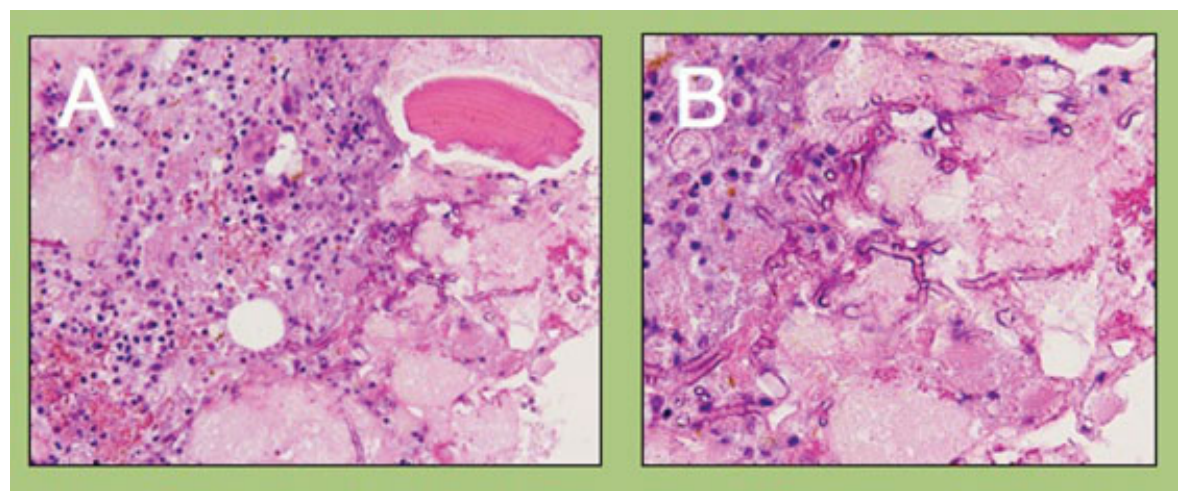

Fig. 2 (A, B) Nonseptate irregular fungiform structures compatible with Rhizopus spp. 
total knee arthroplasty (TKA) replacing the bone defect and restoring joint function. Plates were cemented on both sides of the femoral stem to improve femoral stability (-Fig. 3 ).

After a follow-up of 18 months, the patient exhibited no signs or symptoms of infection, and had an acceptable range of motion (0-90 degrees). Radiographs showed a good alignment of the extremity and no osteolysis signs. The patient returned to his normal work activity.

\section{Discussion}

Infection following knee arthroscopy is usually induced by pyogenic bacteria. Infection rates vary considerably throughout the literature, with the prevalence of deep knee infection ranging from 0.3 to $1.7 \%$. In most cases, the infection does not cause catastrophic results. ${ }^{1,2}$

Only 10 cases of fungal osteomyelitis with catastrophic bone destruction following ACL reconstruction were reported (-Table 1).

Burke and $\mathrm{Zych}^{6}$ described the first case in a 34-year-old otherwise healthy woman who had undergone ACL reconstruction with a bone-patellar tendon-bone autograft. Destructive osteomyelitis resulted in a large cavity in the proximal tibia. Phycomycosis infection was diagnosed on tissue histological analysis. No massive bone resection was needed; surgical treatment consisted of extensive metaphyseal debridement and excision of the medial articular cartilage. Intravenous amphotericin was changed to amphotericin B lipid complex due to toxicity, and applied over a period of 6 weeks. Reconstructive surgery was not performed. The infection healed, but with a substantial bone defect resulting in varus deformity and limited, painful knee motion., ${ }^{1,2}$

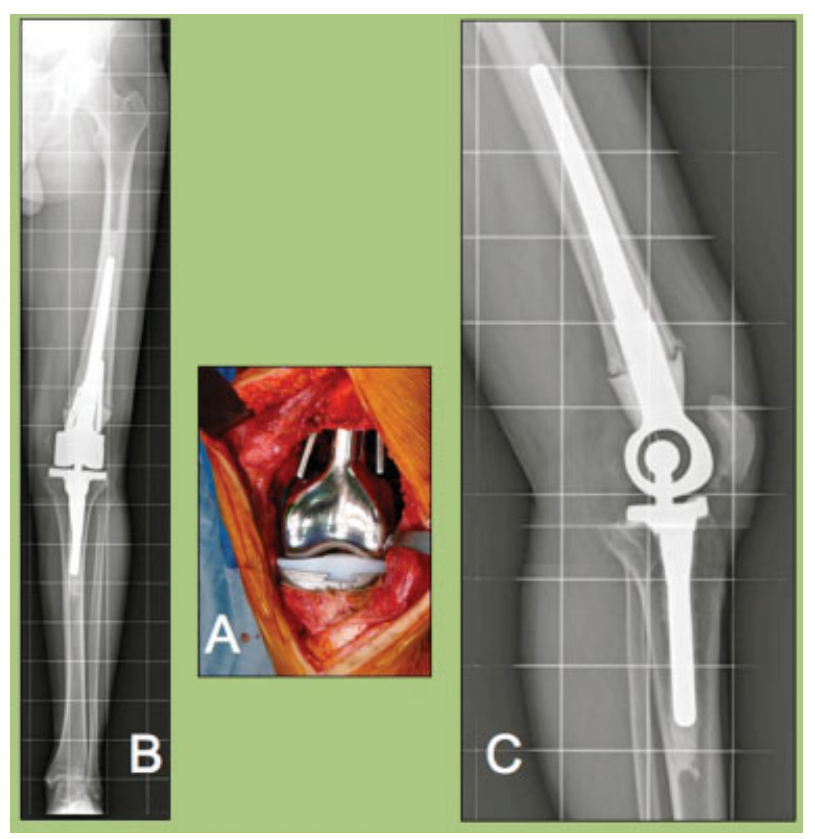

Fig. 3 (A-C) Revision total knee arthroplasty with femoral and tibial cemented stems (Mutars KRI; Implantcast, Buxtehude, Germany) and two dynamic compression plates also cemented on both sides of femoral stem.
Muscolo et $\mathrm{al}^{1}$ reported the largest number of clinical outcomes after fungal knee infection, in the literature examined. Six patients with mycotic infection following ACL reconstruction were reviewed. Each was immunocompetent. Fungal infection was diagnosed based on pathologic samples; Rhizopus species were isolated in five cases, with the sixth case caused by $C$. albicans. Each case had massive bone loss following radical debridement (mean bone loss $12.8 \mathrm{~cm}$ ). All patients were treated with a two-stage revision technique, using cements spacers and intravenous antifungal treatment over a period of 6 weeks before the reconstruction surgery. At first amphotericin B was used, but in four patients this was changed to liposomal amphotericin when the patients showed renal toxicity. Three patients received reconstruction with an allograft and a revision TKA, two with hemicylindrical allografts and one with arthrodesis secondary to extensor mechanism injury. ${ }^{1}$

Wilkins et $\mathrm{al}^{4}$ described a 51-year-old man who had undergone ACL repair and subsequently developed clinical evidence of infection. Fungal cultures were positive for Rhizopus spp. A three-stage revision technique was used. After radical debridement, a cement spacer loaded with amphotericin B was implanted in the resulting defect. Liposomal amphotericin endovenous was administered over the ensuing 6 weeks. The patient was discharged, and for 16 weeks he received a course of posaconazole (oral) as an antifungal. At 10 months after initial presentation, reconstructive surgery was performed with a revision TKA. ${ }^{4}$

Sun et $\mathrm{al}^{5}$ reported on a 23 -year-old man who received ACL reconstruction with a quadrupled hamstring tendon autograft. Several arthroscopic debridements were performed, with serial bacterial cultures all negative. After open debridement was performed 50 days after ACL reconstruction, pathologic examination of bone tissue revealed Aspergillus with Ybranched, septate hyphae. The open debridement involved a distal femoral bone loss of $12 \mathrm{~cm}$. This was treated with bone transport to achieve a solid knee arthrodesis. ${ }^{5}$

Antkowiak et $\mathrm{al}^{2}$ presented a case of chondrolysis of the tibial plateau caused by Aspergillosis, following ACL reconstruction using a quadruple hamstring autograft. The patient was a healthy 13-year-old female athlete. Infection was not considered significant in the initial diagnosis, so a fresh osteochondral hemitibial plateau/meniscus allograft was used to restore the articular surface. Postoperatively, Aspergillus grew in one culture taken from the tibial canal; therefore, the patient was given intravenous voriconazole and caspofungin for 2 weeks, followed by 12 months of oral voriconazole. The patient was also returned to the operating room for tibial canal debridement. Ultimately, a good result was achieved in terms of pain and range of motion. ${ }^{2}$

To our knowledge, our case of mycotic osteomyelitis following a simple and routine arthroscopic partial-knee meniscectomy is the first case reported.

Consistent with the most common fungus reported in the reviewed literature, Rhizopus was isolated in fungal cultures, and nonseptate fungal structures were found in the pathologic study. The clinical symptoms and physical signs in fungal osteomyelitis were less clear and definitive than in 
Table 1 Comparative table of cases reported in the literature

\begin{tabular}{|c|c|c|c|c|c|c|c|}
\hline Author & Initial surgery & $\begin{array}{l}\text { Pathologic } \\
\text { organism }\end{array}$ & $\begin{array}{l}\text { Delay in } \\
\text { diagnosis (d) }\end{array}$ & $\begin{array}{l}\text { Bone } \\
\text { loss }(\mathrm{cm})\end{array}$ & Systemic antifungal & $\begin{array}{l}\text { Systemic } \\
\text { antifungal } \\
\text { (wk) }\end{array}$ & $\begin{array}{l}\text { Reconstruction } \\
\text { surgery }\end{array}$ \\
\hline Burke and Zych (2002) & ACL reconstruction & Phycomycoses & 180 & 30 & $\begin{array}{l}\text { Amphotericin B } \\
\text { Lipid complex ev }\end{array}$ & 6 & No \\
\hline \multirow[t]{6}{*}{ Muscolo et al (2009) } & $\mathrm{ACL}$ reconstruction & Rhizopus & 38 & 14 & Amphotericin $\mathrm{B}^{\mathrm{a}} \mathrm{ev}$ & 6 & $\begin{array}{l}\text { Allograft }+ \\
\text { revision TKA }\end{array}$ \\
\hline & $\mathrm{ACL}$ reconstruction & Rhizopus & 60 & 9.5 & Amphotericin $\mathrm{B}^{\mathrm{a}}$ ev & 6 & $\begin{array}{l}\text { Hemicylindrical } \\
\text { intercalary allograft }\end{array}$ \\
\hline & $\mathrm{ACL}$ reconstruction & Rhizopus & 120 & 10.5 & Amphotericin $\mathrm{B}^{\mathrm{a}} \mathrm{ev}$ & 6 & $\begin{array}{l}\text { Allograft }+ \\
\text { revision TKA }\end{array}$ \\
\hline & ACL reconstruction & Rhizopus & 90 & 13 & Amphotericin $B^{a}$ ev & 6 & $\begin{array}{l}\text { Allograft }+ \\
\text { revision TKA }\end{array}$ \\
\hline & $\mathrm{ACL}$ reconstruction & Rhizopus & 150 & 14 & Amphotericin $\mathrm{B}^{\mathrm{a}} \mathrm{ev}$ & 6 & $\begin{array}{l}\text { Allograft } \\
\text { intercalary } \\
\text { arthrodesis }\end{array}$ \\
\hline & $\mathrm{ACL}$ reconstruction & $\begin{array}{l}\text { Candida } \\
\text { albicans }\end{array}$ & 90 & 11 & Amphotericin $\mathrm{B}^{\mathrm{a}} \mathrm{ev}$ & 6 & $\begin{array}{l}\text { Hemicylindrical } \\
\text { intercalary } \\
\text { allograft }\end{array}$ \\
\hline \multirow[t]{2}{*}{ Wilkins et al (2009) } & \multirow[t]{2}{*}{$\mathrm{ACL}$ reconstruction } & \multirow[t]{2}{*}{ Rhizopus } & \multirow[t]{2}{*}{48} & \multirow[t]{2}{*}{12.7} & $\begin{array}{l}\text { Liposomal } \\
\text { amphotericin ev }\end{array}$ & 6 & \multirow[t]{2}{*}{ Revision TKA } \\
\hline & & & & & Posaconazole oral & 16 & \\
\hline Sun et al (2012) & ACL reconstruction & Aspergillus & 53 & 12 & Unknown & - & $\begin{array}{l}\text { Bone transport } \\
\text { arthrodesis }\end{array}$ \\
\hline \multirow[t]{2}{*}{ Antkowiak et al (2011) } & \multirow[t]{2}{*}{$\mathrm{ACL}$ reconstruction } & \multirow[t]{2}{*}{ Aspergillus } & \multirow[t]{2}{*}{94} & \multirow[t]{2}{*}{-} & $\begin{array}{l}\text { Voriconazole }+ \\
\text { Caspofungin ev }\end{array}$ & 2 & \multirow[t]{2}{*}{$\begin{array}{l}\text { Hemitibial plateau } \\
\text { allograft }\end{array}$} \\
\hline & & & & & Voriconazole oral & 12 & \\
\hline \multirow[t]{2}{*}{ This study } & \multirow[t]{2}{*}{$\begin{array}{l}\text { Arthroscopic } \\
\text { meniscectomy }\end{array}$} & \multirow[t]{2}{*}{ Rhizopus } & \multirow[t]{2}{*}{67} & \multirow[t]{2}{*}{9} & $\begin{array}{l}\text { Liposomal } \\
\text { amphotericin ev }\end{array}$ & 2 & \multirow[t]{2}{*}{$\begin{array}{l}\text { Revision TKA + } \\
\text { two plates }\end{array}$} \\
\hline & & & & & Posaconazole oral & 10 & \\
\hline
\end{tabular}

Abbreviations: $\mathrm{ACL}$, anterior cruciate ligament; ev, endovenous; TKA, total knee arthroplasty.

aTreatment for four patients was changed from amphotericin B lipid complex after they showed evidence of renal toxicity.

pyogenic infections, and did not subside despite the usual empiric antibiotherapy and arthroscopic debridements; in addition, multiple cultures showed negative results.

It should be noted that positive bacterial cultures do not exclude a coexisting fungal infection. Therefore, a high index of suspicion during early diagnosis and treatment is essential.

There are no consensus treatment guidelines for such fungal infections. It seems that radical debridement coupled with prolonged antifungal therapy is the key to limb salvage procedures. The open debridement should include massive bone resection to deal with severe bone necrosis, based on the intraoperative findings. Furthermore, it seems most cases would benefit from a two-stage revision procedure using antifungal-impregnated cement spacers (voriconazole, amphotericin). ${ }^{1,2,4}$

The type of antifungal and duration of treatment are variable, according to the literature reviewed. Most cases were begun with amphotericin B or liposomal amphotericin and followed with oral azole (voriconazole, posaconazole).,4 Candida albicans and Aspergillus fumigatus can produce biofilms on host tissues and medical devices, which are highly resistant to antifungal treatment. Echinocandins could potentially improve clinical outcomes in the treatment of biofilm infections. ${ }^{7-10}$ In our case, antifungal therapy was continued for 3 months. At the outset, the patient was treated with intravenous liposomal amphotericin B over 3 weeks, maintaining strict renal function control. Later, posaconazole at $800 \mathrm{mg} /$ day was used as an at-home oral treatment over 2 additional months.

Reconstruction surgery details will depend on the extent and nature of the bone defect and the degree of extensor mechanism injury. Muscolo et $\mathrm{al}^{1}$ reported a case resolved with an allograft intercalary arthrodesis. Sun et $\mathrm{al}^{5}$ achieved knee arthrodesis by performing a bone transport, employing the Ilizarov technique. Most cases were reconstructed with a revision TKA, some in association with an intercalary bone allograft. Our patient was also treated with a revision TKA (Mutars KRI; Implantcast, Buxtehude, Germany) with cemented stems. Dynamic compression plates were also placed on both sides of the femoral stem to improve femoral stability.

In conclusion, fungal osteomyelitis following arthroscopic procedures is extremely unusual in immunocompetent patients. Delayed diagnosis is common, so severe bone lesions are common in these cases. We should consider this condition as a possibility in cases of high clinical suspicion index and poor response to standard therapy. A two-stage procedure including radical debridement is the key to a successful outcome. Following the first-stage procedure, prolonged 
and specific antifungal therapy must be used. Usually, the reconstruction stage requires complex techniques, including revision TKA or arthrodesis.

\section{References}

1 Muscolo DL, Carbo L, Aponte-Tinao LA, Ayerza MA, Makino A. Massive bone loss from fungal infection after anterior cruciate ligament arthroscopic reconstruction. Clin Orthop Relat Res 2009; 467(9):2420-2425

2 Antkowiak TT, Polage CR, Wiedeman JA, Meehan JP, Jamali AA. Chondrolysis of the tibial plateau caused by articular aspergillosis after ACL autograft reconstruction: management with a fresh osteochondral allograft: a case report. J Bone Joint Surg Am 2011;93(21):e1241-e1246

3 Babcock HM, Matava MJ, Fraser V. Postarthroscopy surgical site infections: review of the literature. Clin Infect Dis 2002;34(1): $65-71$

4 Wilkins RM, Hahn DB, Blum R. Bread mold osteomyelitis in the femur. Orthopedics 2009;32(5):362
5 Sun L, Zhang L, Wang K, Wang W, Tian M. Fungal osteomyelitis after arthroscopic anterior cruciate ligament reconstruction: a case report with review of the literature. Knee 2012;19(5): 728-731

6 Burke WV, Zych GA. Fungal infection following replacement of the anterior cruciate ligament: a case report. J Bone Joint Surg Am 2002;84-A(3):449-453

7 Pemán J, Cantón E, Valentín A. Activity of anidulafungin against Candida biofilms [in Spanish]. Rev Iberoam Micol 2008;25(2): 124-128

8 Robbins N, Uppuluri P, Nett J, et al. Hsp90 governs dispersion and drug resistance of fungal biofilms. PLoS Pathog 2011;7(9): e1002257

9 Chatzimoschou A, Katragkou A, Simitsopoulou M, et al. Activities of triazole-echinocandin combinations against Candida species in biofilms and as planktonic cells. Antimicrob Agents Chemother 2011;55(5):1968-1974

10 Toulet D, Debarre C, Imbert C. Could liposomal amphotericin B (LAMB) lock solutions be useful to inhibit Candida spp. biofilms on silicone biomaterials? J Antimicrob Chemother 2012;67(2): 430-432 